\title{
VARIATION DE LA VALEUR ALIMENTAIRE DES LEVURES DE DISTILLERIE SUIVANT LEUR ORIGINE ET LEUR MODE DE PRÉPARATION
}

PAR

\author{
G. CHARLET-LERY, HEIM DE BALZAC, A. M. LEROY (1) \\ Laboratoire de Recherches de Zootechnie \\ Institut National Agronomique, Paris.
}

L'ensemble des études déjà effectuées sur les levures de distillerie utilisées pour l'alimentation du bétail $(\mathrm{I}, 2,3)$ a montré le grand intérêt alimentaire de ces produits, mais a mis en évidence l'irrégularité de leur composition. A la suite des essais faits par deux d'entre nous sur l'utilisation des levures dans 1'alimentation des poules pondeuses et des poussins (2), nous avons été conduits à reprendre nos essais sur poussins avec différents types de levure dont voici les principales caractéristiques : Levures de betterave $\mathrm{A}$ : lavées avec 2 volumes d'eau et séchées à haute température.

Levures de betterave $\mathrm{B}$ : non lavées et séchées à haute température. Levures de betterave $\mathrm{C}$ : lavées avec I volume d'eau et séchées à haute température.

Levures de betterave $D$ : centrifugées après distillation.

Levures de vinasse $\mathrm{E}_{\mathrm{i}}$ : non lavées et séchées à haute température.

Levures de mélasse $F$ : lavées avec 4 volumes d'eau et séchées à haute température.

Levures de mélasse $\mathrm{G}$ : lavées avec 4 volumes d'eau et séchées à basse température.

Les expériences se sont poursuivies en deux temps : dans une première série d'essais, nous avons comparé les levures $\mathrm{B}, \mathrm{C}, \mathrm{D}, \mathrm{E}$; dans une seconde série, les levures A, B, F, G. De cette façon, le lot levure B nous a servi de lot témoin, et il nous a été possible, en admettant que les résultats enregistrés avec le lot levure $B$ auraient dû être constants, d'établir un coefficient arithmétique de correction pour amener la seconde série au niveau de la première série d'essais.

Les 200 animaux en expérience ont été répartis en 8 lots de 25 aussi homogènes que possible. Pour le premier essai nous avons utilisé

(1) Avec l'assistance technique de A. Bouchardeau. 
des coquelets Leghorn blancs; pour le deuxième des poussins gâtinais ; la proportion de mâles et de femelles était la même pour tous les lots. Pendant toute la durée de l'expérience, de la naissance jusqu'à l'âge de 6 semaines, les animaux ont reçu des régimes qui ne se différenciaient qué par la présence de l'une ou l'autre des levures précitées. Nous avons porté le taux de levure à $7 \%$. Un pourcentage moindre aurait entraîné des variations trop faibles entre nos lots; une teneur plus élevée nous éloignait par trop des quantités normalement utilisées dans les aliments commerciaux pour poussins.

La ration était ainsi composée :

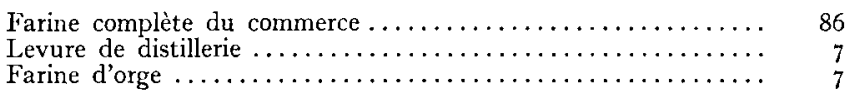

La farine du commerce répondait à l'analyse suivante :

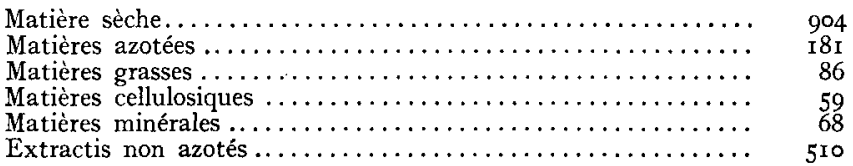

Le mélange total apportait, selon l'origine des levures, entre 185 et $\mathrm{r} 93 \mathrm{~g}$ de matières azotées totales et 0,95 unités fourragères par $\mathrm{kg}$.

Les différentes levures se caractérisaient comme suit:

\begin{tabular}{|c|c|c|c|c|c|}
\hline & $\begin{array}{c}\text { Matière sèche } \\
\%\end{array}$ & \begin{tabular}{|} 
Matières \\
azotées totales \\
dans la \\
matière sèche \\
$\%$
\end{tabular} & $\begin{array}{c}\text { Matières } \\
\text { minérales } \\
\text { \% }\end{array}$ & $\begin{array}{c}\text { Potassium (1) } \\
\text { dans la } \\
\text { matière sèche } \\
\%\end{array}$ & $\begin{array}{c}\text { Indice de } \\
\text { consommation } \\
\text { (jusqu'à l'âge } \\
\text { de } 6 \text { semaines) }\end{array}$ \\
\hline 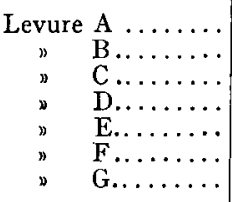 & $\begin{array}{l}90,82 \\
90,45 \\
90,57 \\
90,52 \\
83,00 \\
90,67 \\
90,96\end{array}$ & $\begin{array}{l}42,62 \\
37,59 \\
42,63 \\
35,28 \\
3^{1,23} \\
42,00 \\
42,84\end{array}$ & $\begin{array}{r}4,34 \\
6,77 \\
6,45 \\
6,80 \\
10,43 \\
6,35 \\
5,21\end{array}$ & $\begin{array}{l}1,39 \\
1,92 \\
1,63 \\
0,60 \\
3,39 \\
2,25 \\
1,39\end{array}$ & $\begin{array}{l}2,25 \\
2,14 \\
2,15 \\
2,13 \\
2,35 \\
2,24 \\
2,29\end{array}$ \\
\hline
\end{tabular}

(1) Dosage effectué par la méthode au perchlorate de potassium.

A la fin de la $6^{\mathrm{e}}$ semaine, le poids moyen de nos animaux a varié de $443 \mathrm{~g}$ à $536 \mathrm{~g}$. Comme dans nos précédentes expériences, nous n'avons pas enregistré de mortalité, ni constaté la présence de phénomènes de rachitisme.

L,es indices de consommation ( $\mathrm{kg}$ de nourriture consommé par $\mathrm{kg}$ de gain de poids vif) ont été calculés pour la durée de l'expérience et figurent dans le tableau précédent.

L'indice de consommation moyen des lots recevant de la levure de betterave s'élève à $2, \mathrm{I} 7$; la même valeur pour les lots recevant de la 
levure de mélasse ou de vinasse est de 2,29. La différence entre ces deux résultats est significative $(t>3)$ et indépendante des teneurs en matières azotées totales dont les moyennes sont voisines 39,53 et $38,69 \%$ et non significativement différentes. Ces résultats coïncident avec ceux trouvés par FÉVRIER, LEROY et Roche dans un récent travail (3).

Le coefficient de corrélation entre les taux de potassium des levures et les indices de consommation est égal à $+0,5^{8} \pm 0,17$. Bien que ce coefficient ne soit pas très élevé, il semble que l'on puisse émettre l'hypothèse que 1a richesse en potassium des levures est un des facteurs limitants de sa valeur alimentaire. Cette hypothèse demanderait à être confirmée.

Au cours de cette expérience, nous constatons une fois de plus l'irrégularité de la composition des levures entraînant des résultats fort différents pour leur utilisation alimentaire. Il serait nécessaire de poursuivre ces travaux pour mettre en évidence les causes exactes des résultats observés et étudier les hypothèses énoncées à ce sujet.

\section{BIBLIOGRAPHIE}

Leroy (A.-M.), FÉvrier (R.). -- Émploi de la levure de distillerie pour l'alimentation des animaux domestiques, Ann. Agron., I947, 4.

Charlett (P.), Charlet-Líry (G.), Leroy (A.-M.). - Utilisation des levures de distillerie dans l'alimentation des volailles. Ann. Zootechnie, I952, 4, 33 .

FÉvrier (R.), LERoy (A.-M.), Roche (J.). - Influence du mode de séchage sur la valeur alimentaire de la levure de distillerie. Ann. Zootechnie, I 952,4 , I. 